\title{
OPTIMASI PARAMETER PERMESINAN TERHADAP WAKTU PROSES PADA PEMROGRAMAN CNC MILLING DENGAN BERBASIS CAD/CAM
}

\author{
I G.N.K. Yudhyadi ${ }^{\star}$, Tri Rachmanto, Adnan Dedy Ramadan, \\ Teknik Mesin, Fakultas Teknik, Universitas Mataram, Jl. Majapahit no. 62, Mataram, NTB, \\ 83125, Indonesia \\ *Email: ik_yadhy@hotmail.com
}

\begin{abstract}
Milling process is one of many machining processes for manufacturing component. The length of time in the process of milling machining is influenced by selection and design of machining parameters including cutting speed, feedrate and depth of cut. The purpose of this study to know the influence of cutting speed, feedrate and depth of cut as independent variables versus operation time at CNC milling process as dependent variables. Each independent variable consists of three level of factors; low, medium and high.Time machining process is measured from operation time simulation program, feed cut length and rapid traverse length. The results of statistically from software simulation MasterCam X Milling, then do comparison to CNC Milling machine. The data from experiments was statistical analyzed by Anova and Regression methods by software minitab 16. Results show that the greater feedrate and depth of cut shorten the operation time of machinery, whereas cutting speed is not significant influence. Depth of cut has the most highly contribution with the value of $49.56 \%$, followed by feedrate $43 \%$ and cutting speed $0.92 \%$. Optimal time of machining process total is 71.92 minutes, with machining parameter on the condition cutting speed is $75360 \mathrm{~mm} /$ minutes, feedrate is 800 $\mathrm{mm} /$ minutes and depth of cut $=1 \mathrm{~mm}$. Results of comparison time machining process in software Mastercam X milling with CNC Milling machine indicates there is difference not significant with the value of $0,35 \%$.
\end{abstract}

Keywords: machining parameter, CNC milling, optimize, CAD/CAM, anova.

\section{PENDAHULUAN}

Perkembangan teknologi manufaktur yang semakin pesat dan semakin tingginya kompetisi antara produsen produk-produk manufaktur, kebutuhan akan kualitas produk yang tinggi (high quality product) yang dihasilkan dengan kecepatan produksi yang tinggi (high speed manufacturing). Dimana pada saat ini dalam pengembangan dan perencanaan produk tidak terlepas akan kebutuhan teknologi, dengan kebutuhan yang sangat tinggi maka dikembangkanlah sistem otomasi. Otomasi dapat didefinisikan sebagai teknologi yang berlandaskan pada aplikasi sistem mekanik, elektronik dan computer, sehingga pekerjaan tahap pengembangan meliputi perencanaan, persiapan, perakitan, instalasi, pemrograman, inspeksi, komisioning. Dewasa ini filosofi yang banyak digunakan adalah Concurrent Engineering (CE). Concurrent Engineering menurut U. S. Institute of Defence adalah suatu pendekatan sistematis terhadap desain produk dan proses yang terkait secara bersamaan dan terintegrasi, termasuk di dalamnya manufacturing dan pendukung lainnya.

Kesemuanya itu membutuhkan sistem pendukung proses manufaktur yang handal. Salah satu pendukung tersebut adalah sistem
CAD/CAM. CAD/CAM memiliki dua bagian yakni desain gambar CAD (Computer Aided Design) dan desain gambar CAM (Computer Aided Machine). Desain yang dihasilkan oleh software CAD/CAM ini nantinya akan diubah menjadi bahasa pemrograman ( $G$ Code) yang selanjutnya dikerjakan oleh mesin CNC (Computer Numerical Control). Penggunaan mesin CNC sebagai mesin perkakas dalam proses permesinan modern semakin banyak dijumpai dalam industri manufaktur, CNC milling dalam hal ini memiliki fungsi untuk mengerjakan suatu komponen secara efisien, hemat waktu, dan hemat biaya. Dengan program yang telah disiapkan sebelumnya, komponen-komponen yang sama dapat diproduksi berkali-kali dengan akurasi yang tepat (Krar dkk, 1999).

Proses permesinan yang dilakukan pada mesin CNC milling adalah proses penyayatan benda kerja menggunakan alat potong yang berputar. Beberapa parameter yang bisa mempengaruhi proses permesinan adalah cutting speed yang berhubungan dengan dengan putaran motor dan diameter alat potong, feedrate berhubungan dengan kecepatan pemakanan dan depth of cut (kedalaman pemakanan). Ketiga parameter pemakanan tersebut merupakan parameter 
penting dalam sebuah proses permesinan. Pemilihan parameter pemotongan yang tepat dalam proses permesinan adalah hal yang sangat penting untuk meraih kualitas produk yang baik serta proses yang ekonomis dan produktif (Draganescu dkk, 2001).

Kualitas produk hasil CNC milling dapat dilihat dari waktu proses pengerjaanya. Oleh karena itu hasil CNC milling perlu diperhatikan dan dicari solusi untuk mendapatkan waktu yang optimal. Untuk mengatasi hal ini, maka perlu diadakakn penelitian sehingga nantinya dapat melakukan variasi parameter permesinan untuk menghasilkan waktu proses yang optimal pada pemrograman CNC Milling. Dari ketiga parameter tersebut diperkirakan akan mempengaruhi waktu proses dalam pemrograman mesin $\mathrm{CNC}$ Milling. Maka pada penelitian ini akan dicari waktu yang optimal dalam pemrograman pada CNC Milling berdasarkan variasi dari parameter-parameter tersebut selanjutnya untuk mengetahui pengaruh ketiga parameter tersebut.

\section{TINJAUAN PUSTAKA \\ Proses Permesinan}

Proses permesinan frais (milling) adalah proses penyayatan benda kerja menggunakan alat potong dengan mata potong jamak yang berputar (Rochim, 1993). Proses penyayatan dengan gigi potong yang banyak yang mengitari pisau ini bisa menghasilkan proses permesinan lebih cepat. Permukaan yang disayat bisa berbentuk datar, menyudut, atau melengkung. Permukaan benda kerja bisa juga berbentuk kombinasi dari beberapa bentuk. Mesin yang digunakan untuk memegang benda kerja, memutar pisau, dan penyayatannya disebut mesin frais (milling machine).

Proses permesinan milling sering digunakan dalam pembuatan cetakan (mould), untuk pekerjaan perataan permukaan, pembentukan roda gigi, pembentukan pola permukaan, dan pekerjaan bor. Pada proses permesinan milling terdapat beberapa parameter yang berpengaruh terhadap kekasaran permukaan komponen diantaranya adalah kecepatan pemotongan atau kecepatan putaran spindel, kedalaman pemakanan, geometri pahat, kecepatan pemakanan dan penggunaan cairan pendingin. Proses terbentuknya geram telah diteliti untuk menemukan bentuk yang mendekati ideal, berapa kecepatan (speed), gerak makan (feed) dan parameter yang lain, yang di masa yang lalu diperoleh dengan perkiraan oleh para ahli dan operator proses permesinan.

\section{CAD/CAM \& CNC}

CAD/CAM merupakan program permesinan yang sangat efektif untuk proses pembentukan, dimana bentuk-bentuk yang tidak dapat diproses dengan mesin konvensional maka dengan mengunakan proses CAD/CAM tidak lagi mendapat kesulitan. Product life cycle yang makin singkat menuntut waktu pengembangan produk dan waktu produksi yang cepat. Keterkaitan berbagai parameter yang rumit dan saling berinteraksi dapat diselesaikan dengan cepat. Di dunia industri saat ini, fungsi CAD sangat vital. Dengan CAD kesalahan dalam proses pembuatan desain bisa diminimalkan, yang berarti waktu dan biaya dapat sangat dioptimalkan.

Sebagai software CAD, solidworks dipercaya sebagai perangkat lunak untuk membantu proses desain suatu benda atau bangunan dengan mudah. Keunggulan solidworks dari software CAD lain adalah mampu menyediakan sketsa 2D yang dapat diupgrade menjadi bentuk 3D. Software ini juga dapat melakukan simulasi pada desain yang telah buat. Analisi kekuatan desain juga dapat dilakukan secara sederhana dengan solidworks dan dapat membuat desain animasi menggunakan fitur yang telah disediakan solidworks.

Computer aided manufacturing (CAM) adalah penggunaan software komputer untuk mengontrol tools mesin ataupun bagian mesin lainnya yang berhubungan dengan proses permesinan. Definisi lain dari CAM juga berarti penggunaan komputer yang berfungsi untuk membantu dalam semua perencanaan manufaktur, termasuk didalamnya perencanaan, managemen, transportasi dan penyimpanan (Ricky, 2009). Integrasi CAM dengan sistem CAD menghasillan proses manufaktur yang lebih cepat dan lebih efisien. Digunakanlah mesin CNC untuk melakukan proses permesinan dan perancangan. Di banyak kasus sistem CAM akan bekerja dengan perancangan CAD yang dibuat di lingkungan 3 dimensi. Programmer CNC akan menentukan operasi mesin dan sistem CAM yang akan membuat program CNC. Kompatibilitas sistem CAD/CAM dibatasi untuk kebutuhan pengenalan kembali konfigurasi bidang kerja bagi sistem CAM. Dengan kata lain perangkat lunak CAM biasanya terdapat bersama dengan mesin CNC. 


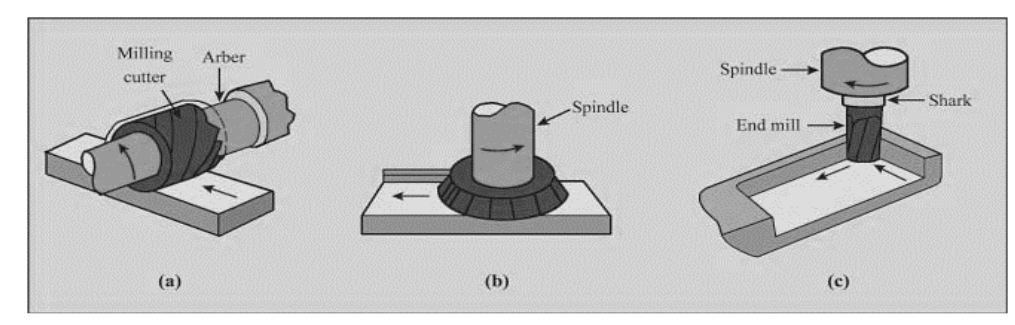

Gambar 1. Tiga klasifikasi proses frais : (a) Frais periperal (slab milling), (b) frais muka (face milling), dan (c) frais jari (end milling).

MasterCAM merupakan perangkat lunak yang dikembangkan dari CNC Software Inc, dimana software ini sebelumnya sudah familiar di pemesinan, MasterCAM adalah salah satu program CAM yang cukup popular. Software MasterCAM memungkinkan pengerjaan mendesain, kemudian merencanakan proses pembuatannya melalui simulasi yang dilaksanakan secara berurutan atau simultan dan kemudian membuatnya menjadi suatu program NC

Hasil perpaduan teknologi komputer dan teknologi mekanik inilah yang selanjutnya dinamakan CNC (Computer Numerical Control). Sistem pengoperasian CNC menggunakan program yang dikontrol langsung oleh komputer. Secara umum konstruksi mesin perkakas CNC dan sistem kerjanya adalah sinkronisasi antara komputer dan mekaniknya. Jika dibandingkan dengan mesin perkakas konvensional yang setaraf dan sejenis, mesin perkakas CNC lebih unggul baik dari segi ketelitian (accurate), ketepatan (precision), fleksibilitas, dan kapasitas produksi.

Mesin CNC adalah suatu mesin yang dikontrol oleh komputer dengan menggunakan bahasa numerik (data perintah dengan kode angka, huruf dan simbol) sesuai standart ISO. Sistem kerja teknologi CNC ini akan lebih sinkron antara komputer dan mekanik, sehingga bila dibandingkan dengan mesin perkakas yang sejenis, maka mesin perkakas CNC lebih teliti, lebih tepat, lebih fleksibel dan cocok untuk produksi masal. Dengan dirancangnya mesin perkakas CNC dapat menunjang produksi yang membutuhkan tingkat kerumitan yang tinggi dan dapat mengurangi campur tangan operator selama mesin beroperasi. Untuk mengoperasikan mesin-mesin CNC diperlukan software. Software yang digunakan adalah operating system software dan machine interface software. Software digunakan untuk Operating system menginterprestasikan progam korespondensi antara kontrol mesin. Machine interface mengoperasikan link antara NC dan membangkitkan sinyal dengan drive dari software digunakan untuk komputer dan mesin CNC sehingga mesin dapat beroperasi. Mesin CNC yang terhubung dengan komputer tidak hanya memungkinkan operator untuk menjalankan program tetapi juga memodifikasi program tersebut, baik setelah diinputkan ataupun dijalankan.

\section{Parameter Permesinan}

Parameter proses permesinan frais adalah, dasar-dasar perhitungan yang digunakan untuk menentukan perhitungan perhitungan dalam proses pemotongan/penyayatan permesinan frais diantaranya, kecepatan potong ( $V c)$, kecepatan putaran mesin (rpm), kecepatan pemakanan $(V f)$ dan kedalaman pemotongan (depth of cut). Pada proses permesinan dengan menggunakan mesin milling terdapat beberapa parameter pemotongan, antara lain: (1). Kecepatan potong (Cutting speed)

$$
\text { Kecepatan potong merupakan }
$$
kecepatan gerak putar pahat, yang dinyatakan dalam meter/menit. Kecepatan gerak pahat tergantung dari bahan benda kerja yang akan di-milling dan bahan dari pahat potong itu sendiri, untuk mencari kecepatan pemotong rumusnya dengan:

$$
V_{c}=\pi d n
$$

Dimana $V_{c}$ adalah kecepatan potong ( $\mathrm{mm} / \mathrm{menit})$, d menunjukan diameter pisau $(\mathrm{mm}), n$ adalah putaran spindle (rpm). 
Tabel 1. Kecepatan potong untuk beberapa jenis bahan.

\begin{tabular}{ccc}
\hline No & Bahan Benda Kerja & $\begin{array}{c}V_{c} \\
(\mathrm{~m} / \text { menit })\end{array}$ \\
\hline 1 & Kuningan, Perunggu keras & $30-45$ \\
2 & Besi tuang & $14-21$ \\
3 & Baja $>70$ & $10-14$ \\
4 & Baja 50-70 & $14-21$ \\
5 & Baja 34-50 & $20-30$ \\
6 & Tembaga, Perunggu lunak & $40-70$ \\
7 & Aluminium murni & $300-500$ \\
8 & Plastik & $60-100$ \\
\hline
\end{tabular}

( Sumber : Sumbodo, 2008)

(2). Putaran spindle (spindle speed)

Kecepatan putaran mesin adalah kemampuan kecepatan putaran mesin dalam satu menit. Dalam hal ini mengingat nilai kecepatan potong untuk setiap jenis bahan sudah ditetapkan secara baku, maka

Tabel 2. Gerak makan (f) untuk berbagai kedalaman potong dan material benda kerja untuk beberapa diameter alat potong (End Mill)

\begin{tabular}{|c|c|c|c|c|c|}
\hline \multirow{3}{*}{ Material } & \multicolumn{5}{|c|}{ Diameter Alat Potong } \\
\hline & \multicolumn{3}{|c|}{ Kedalaman $(1,25 \mathrm{~mm})$} & \multicolumn{2}{|c|}{ Kedalaman ( $6 \mathrm{~mm}$ ) } \\
\hline & $3 \mathrm{~mm}$ & $10 \mathrm{~mm}$ & $12,5 \mathrm{~mm}$ & $10 \mathrm{~mm}$ & $18 \mathrm{~mm}$ \\
\hline $\begin{array}{c}\text { Low-carbon } \\
\text { steel }\end{array}$ & $0,0012-0,025$ & $0,050-0,075$ & $0,075-0,1$ & $0,025-0,050$ & $0,050-0,1$ \\
\hline $\begin{array}{l}\text { High-carbon } \\
\text { steel }\end{array}$ & $0,0003-0,025$ & $0,025-0,075$ & $0,050-0,1$ & $\begin{array}{c}0,0003- \\
0,025\end{array}$ & $0,025-0,1$ \\
\hline $\begin{array}{c}\text { Tool Steel } \\
\text { Cast }\end{array}$ & $0,0012-0,025$ & $0,025-0,075$ & $0,050-0,1$ & $0,025-0,050$ & $0,075-0,1$ \\
\hline $\begin{array}{c}\text { Aluminium } \\
\text { Alloy } \\
\text { Cast }\end{array}$ & 0,05 & 0,075 & 0,125 & 0,075 & 0,2 \\
\hline $\begin{array}{l}\text { Aluminium } \\
\text { Hard }\end{array}$ & 0,025 & 0,075 & 0,125 & 0,075 & 0,15 \\
\hline $\begin{array}{l}\text { Brass \& } \\
\text { Bronze }\end{array}$ & $0,0012-0,025$ & $0,075-0,1$ & $0,1-0,15$ & $0,05-0,075$ & $0,1-0,15$ \\
\hline Plastics & 0,05 & 0,08 & 0,125 & 0,075 & 0,2 \\
\hline
\end{tabular}

(Sumber: Wijanarka, 2011), Catatan: Harga gerak makan $\left(f_{z}\right)$ dalam mm/gigi, sehingga perlu dikalikan dengan jumlah gigi $(z)$.

(4). Kedalaman pemotongan (Depth of cut) Kedalaman potong (a) ditentukan berdasarkan selisih tebal benda kerja awal terhadap tebal benda kerja akhir. Untuk kedalaman potong yang relatif besar diperlukan perhitungan daya potong yang diperlukan untuk proses penyayatan.

Besarnya kedalaman pemakanan berhubungan erat dengan kecepatan pemakanan dan juga dari diameter pahat tersebut. Semakin tinggi kecepatan pemakanan, maka pahat yang digunakan komponen yang bisa diatur dalam proses penyayatan adalah putaran mesin/benda kerja. Nilai putaran dapat dihitung menggunakan persamaan (1).

\section{(3). Kecepatan pemakanan (Feedrate)}

Gerak makan $(f)$ adalah jarak lurus yang ditempuh pisau dengan laju konstan relatif terhadap benda kerja dalam satuan waktu, biasanya satuan gerak makan yang digunakan adalah $\mathrm{mm} /$ menit.

$V_{f}=n f_{z} z$

Dengan $\quad V_{f}$ adalah kecepatan makan ( $\mathrm{mm} /$ menit), $n$ menunjukan putaran spindle (rpm), $z$ adalah jumlah gigi pada pahat (tooth) dan $f_{z}$ adalah kecepatan makan pergigi (mm/tooth) 
penelitian ini berupa gambar benda kerja dengan dimensi seperti Gambar 3. Pengerjaan desain menggunakan software SolidWork 2010 untuk proses CAD-nya, selanjutnya desain gambar dalam bentuk file di transfer ke software MasterCam $X$ untuk dilakukan proses CAM. Dari Software mastercam $x$ akan keluar NC Code yang selanjutnya dapat dipindah ke mesin CNC Milling Mitsubishi M70 untuk dilakukan percobaan lansung. Raw material yang digunakan pada mesin CNC yaitu Resin Polyester dengan pahat berbahan HSS dengan pahat Facemill dan Endmill.

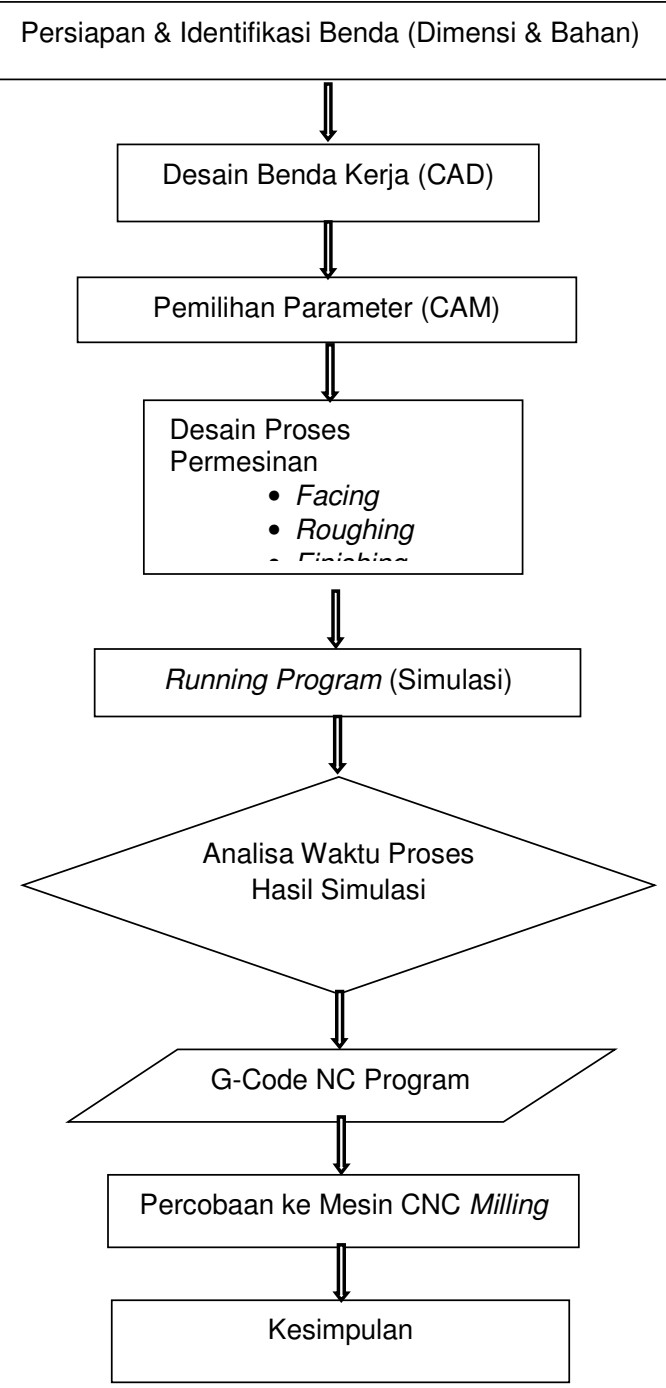

Gambar 2. Diagaram alir penelitian

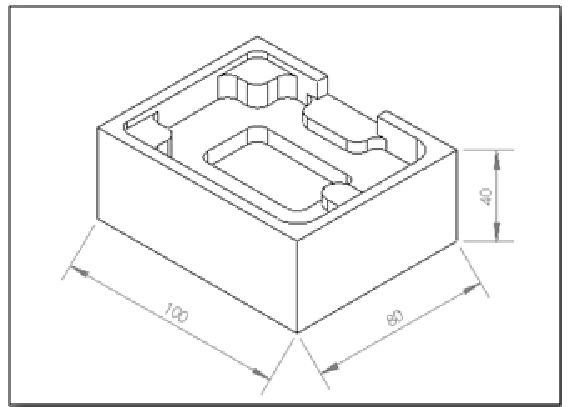

Gambar 3. Desain base feature dari benda kerja.

Pemilihan variabel bebas dan terikat dalam penelitian ini yaitu waktu proses sebagai variable terikat dimana waktu proses adalah waktu aktual dari proses penyayatan benda kerja pada mesin CNC Milling. Pengukuran waktu proses pemesinan dilakukan dengan mensimulasikan proses pemesinan yang nantinya akan diketahui waktu pengerjaanya. Selanjutnya adapun yang menjadi variabel bebas yaitu kecepatan potong (cutting speed), laju pemakanan (feedrate), kedalaman pemakanan (depth of cut).

Dalam penelitian ini menggunakan desain ekperimen berdasarkan pendekatan orthogonal array dengan tiga faktor dan tiga level, dimana kolom merupakan faktor yang dapat diubah dalam eksperimen dan baris merupakan kombinasi level dari faktor dalam eksperimen. Sesuai dengan pola orthogonal didapatkan seperti pada Tabel 3. 
Tabel 3. Faktor parameter dan level penelitian.

\begin{tabular}{ccccc}
\hline & & \multicolumn{3}{c}{ Level } \\
Parameter & Faktor & 1 & 2 & 3 \\
& & Low & Medium & High \\
\hline Cutting Speed $(\mathrm{mm} / \mathrm{menit})$ & A & 56520 & 75360 & 94200 \\
Feedrate $(\mathrm{mm} / \mathrm{menit})$ & $\mathrm{B}$ & 500 & 650 & 800 \\
Depth of cut $(\mathrm{mm})$ & $\mathrm{C}$ & 0,5 & 0,75 & 1 \\
\hline
\end{tabular}

Tabel 4. Desain kombinasi parameter percobaan.

\begin{tabular}{cccc}
\hline \multirow{2}{*}{ Percobaan } & \multicolumn{3}{c}{ Faktor } \\
& A & B & C \\
\hline 1 & 1 & 1 & 1 \\
2 & 1 & 2 & 2 \\
3 & 1 & 3 & 3 \\
4 & 2 & 1 & 2 \\
5 & 2 & 2 & 3 \\
6 & 2 & 3 & 1 \\
7 & 3 & 1 & 3 \\
8 & 3 & 2 & 1 \\
9 & 3 & 3 & 2 \\
\hline
\end{tabular}

\section{Teknik Pengambilan dan Anlisa Data}

Data yang digunakan dalam penelitian ini merupakan data-data hasil dari proses eksperimen mengenai parameter yang diuji, data hasil penelitian yang didapatkan meliputi:

a. Hasil percobaan

Hasil percobaan adalah hasil dari pembuatan toolpath geometry sesuai parameter yang telah ditentukan dalam desain eksperimen.

b. Hasil pengukuran waktu proses permesinan

Hasil pengukuran yang dikumpulkan yaitu hasil pengukuran waktu (Operation Time) dari simulasi proses pemesinan, hasil pengukuran panjang langkah pemotongan (feed cut length), dan hasil pengukuran panjang langkah tanpa pemotongan (rapid traverse length) pada masing-masing percobaan yang dilakukan.

Data yang didapatkan kemudian diolah untuk mendapatkan hubugan antara pengaruh dari tiap-tiap parameter terhadap waktu pemrograman yang dihasilkan dan optimasi waktu dari masing-masing parameter, sehingga waktu yang optimal dari pengujian tersebut merupakan kesimpulan yang dapat diambil. Pada penelitian ini menggunakan analisis ragam (Anova), dimana metode ini digunakan untuk mencari hubungan antara variabel bebas dengan variabel terikatnya, sehingga akan dapat diketahui besarnya pengaruh masing-masing variabel bebas terhadap variabel terikatnya.

\section{HASIL DAN PEMBAHASAN}

\section{Hasil pengambilan data}

Berdasarkan pada metode penelitian yang telah ditetapkan, pelaksanaan penelitian ini dilakukan dengan memvariasikan pengaturan parameter pada setiap percobaannya. Pengukuran waktu proses permesinan sebagai veriabel respon dalam penelitian ini dilakukan dengan mensimulasikan terlebih dahulu proses permesinannya dengan menggunakan software MasterCam $X$ Mill. Dengan mengunakan fasilitas Command 'Setup Sheet' didapatkan data hasil dari tiap-tiap percobaan diantaranya waktu proses permesinan (operation time), panjang langkah pemotongan (feed cut length) dan panjang langkah tanpa pemotongan (rapid tranverse length).

Tabel 5. Hasil pengukuran waktu proses permesinan

\begin{tabular}{cccccccc}
\hline \multicolumn{3}{c}{ Parameter } & \multicolumn{4}{c}{ Toolpath } \\
No & $\begin{array}{c}\text { Cutting Speed } \\
\text { (mm/menit) }\end{array}$ & $\begin{array}{c}\text { Feedrate } \\
\text { (mm/menit) }\end{array}$ & $\begin{array}{c}\text { Depth of } \\
\text { cut }(\mathrm{mm})\end{array}$ & $\begin{array}{c}\text { Face } \\
\text { (menit) }\end{array}$ & $\begin{array}{c}\text { Rough } \\
\text { (menit) }\end{array}$ & $\begin{array}{c}\text { Finish } \\
\text { (menit) }\end{array}$ & $\begin{array}{c}\text { Total } \\
\text { (menit) }\end{array}$ \\
\hline 1 & 56520 & 500 & 0,5 & 16,84 & 143,13 & 28,29 & 188,26 \\
2 & 56520 & 650 & 0,75 & 9,44 & 75,84 & 21,90 & 107,18 \\
3 & 56520 & 800 & 1 & 6,73 & 48,18 & 17,91 & 72,82 \\
4 & 75360 & 500 & 0,75 & 12,24 & 98,33 & 28,29 & 138,86 \\
5 & 75360 & 650 & 1 & 8,26 & 59,10 & 21,90 & 89,26 \\
6 & 75360 & 800 & 0,5 & 10,57 & 89,82 & 17,91 & 118,30 \\
7 & 94200 & 500 & 1 & 10,71 & 76,57 & 28,29 & 115,57 \\
8 & 94200 & 650 & 0,5 & 12,98 & 110,32 & 21,90 & 145,20 \\
\hline
\end{tabular}




\begin{tabular}{llllllll}
\hline \multicolumn{10}{|c}{} & & & & & & \\
\hline 9 & 94200 & 800 & 0,75 & 7,69 & 61,79 & 17,91 & 87,39
\end{tabular}

Tabel 6. Hasil pengukuran panjang langkah pemotongan

\begin{tabular}{cccccccc}
\hline & \multicolumn{3}{c}{ Parameter } & \multicolumn{4}{c}{ Toolpath } \\
No & $\begin{array}{c}\text { Cutting Speed } \\
(\mathrm{mm} / \mathrm{menit})\end{array}$ & $\begin{array}{c}\text { Feedrate } \\
(\mathrm{mm} / \mathrm{menit})\end{array}$ & $\begin{array}{c}\text { Depth of } \\
\text { cut }(\mathrm{mm})\end{array}$ & $\begin{array}{c}\text { Face } \\
(\mathrm{mm})\end{array}$ & $\begin{array}{c}\text { Rough } \\
(\mathrm{mm})\end{array}$ & $\begin{array}{c}\text { Finish } \\
(\mathrm{mm})\end{array}$ & $\begin{array}{c}\text { Total } \\
(\mathrm{mm})\end{array}$ \\
\hline 1 & 56520 & 500 & 0,5 & 8091,96 & 69894,31 & 13598,66 & 91584,92 \\
2 & 56520 & 650 & 0,75 & 5880,97 & 47904,39 & 13598,66 & 67384,02 \\
3 & 56520 & 800 & 1 & 5143,97 & 37217,87 & 13598,66 & 55960,50 \\
4 & 75360 & 500 & 0,75 & 5880,97 & 47904,39 & 13598,66 & 67384,02 \\
5 & 75360 & 650 & 1 & 5143,97 & 37217,87 & 13598,66 & 55960,50 \\
6 & 75360 & 800 & 0,5 & 8091,96 & 69894,31 & 13598,66 & 91584,92 \\
7 & 94200 & 500 & 1 & 5143,97 & 37217,87 & 13598,66 & 55960,50 \\
8 & 94200 & 650 & 0,5 & 8091,96 & 69894,31 & 13598,66 & 91584,92 \\
9 & 94200 & 800 & 0,75 & 5880,97 & 47904,39 & 13598,66 & 67384,02 \\
\hline
\end{tabular}

Tabel 7. Hasil pengukuran panjang langkah tanpa pemotongan Parameter Toolpath

\begin{tabular}{cccccccc} 
& \multicolumn{3}{c}{ Parameter } & \multicolumn{4}{c}{ Toolpath } \\
No & $\begin{array}{c}\text { Cutting Speed } \\
(\mathrm{mm} / \mathrm{menit})\end{array}$ & $\begin{array}{c}\text { Feedrate } \\
(\mathrm{mm} / \mathrm{menit})\end{array}$ & $\begin{array}{c}\text { Depth of } \\
\text { cut }(\mathrm{mm})\end{array}$ & $\begin{array}{c}\text { Face } \\
(\mathrm{mm})\end{array}$ & $\begin{array}{c}\text { Rough } \\
(\mathrm{mm})\end{array}$ & $\begin{array}{c}\text { Finish } \\
(\mathrm{mm})\end{array}$ & $\begin{array}{c}\text { Total } \\
(\mathrm{mm})\end{array}$ \\
\hline 1 & 56520 & 500 & 0,5 & 1659,57 & 5695,14 & 2640,24 & 9994,95 \\
2 & 56520 & 650 & 0,75 & 1344,59 & 4787,00 & 2640,24 & 8771,83 \\
3 & 56520 & 800 & 1 & 1239,59 & 4368,32 & 2640,24 & 8248,15 \\
4 & 75360 & 500 & 0,75 & 1344,59 & 4787,00 & 2640,24 & 8771,83 \\
5 & 75360 & 650 & 1 & 1239,59 & 4368,32 & 2640,24 & 8248,15 \\
6 & 75360 & 800 & 0,5 & 1659,57 & 5695,14 & 2640,24 & 9994,95 \\
7 & 94200 & 500 & 1 & 1239,59 & 4368,32 & 2640,24 & 8248,15 \\
8 & 94200 & 650 & 0,5 & 1659,57 & 5695,14 & 2640,24 & 9994,95 \\
9 & 94200 & 800 & 0,75 & 1344,59 & 4787,00 & 2640,24 & 8771,83 \\
\hline
\end{tabular}

\section{Analisa variansi (Anova)}

Dari hasil percobaan yang telah dilakukan kemudian dilanjutkan dengan analisa mengunakan analisa varian sesuai faktor parameter, level dan pengolahan data berdasarkan statistik Anova untuk mengetahui pengaruh dari masing-masing variabel bebas (cutting speed, feedrate dan depth of cut) terhadap variabel respon (waktu proses pemesinan). Hasil analisa tersebut disajikan dalam bentuk tabel, sebagai berikut.
Tabel 8. Hasil analisis means dari waktu proses

\begin{tabular}{cccc}
\hline \multirow{2}{*}{ Sumber Varian } & \multicolumn{3}{c}{ Nilai rata-rata tiap level } \\
\cline { 2 - 4 } & 1 & 2 & 3 \\
\hline Cutting Speed & 122,75 & 115,47 & 116,05 \\
Feedrate & 147,56 & 113,88 & 92,84 \\
Depth of cut & 150,59 & 111,14 & 92,55 \\
\hline
\end{tabular}

Tabel 9. Hasil analisa statitistik Anova

\begin{tabular}{ccccccc}
\hline Sumber Variansi & $\mathrm{db}$ & $\mathrm{JK}$ & $\mathrm{JKT}$ & $\mathrm{Fh}$ & Signifikan & $\mathrm{Ft}$ \\
\hline Cutting Speed & 2 & 98,2 & 49,1 & 1,00 & 0,505 & 4,46 \\
Feedrate & 2 & 4572,4 & 2286,2 & 46,53 & 0,021 & 4,46 \\
Depth of cut & 2 & 5269,7 & 2634,9 & 53,63 & 0,018 & 4,46 \\
Error & 2 & 98,3 & 49,1 & & & \\
Total & 8 & 10633,5 & & & & \\
\hline
\end{tabular}

Tabel analisa statistik Anova dengan $\alpha$ $=5 \%$. Nilai dari $\mathrm{F}$ tabel dari masing-masing varian $\left(F_{0.05,} 2,8\right)$ adalah 4,46 , sehingga diketahui bahwa nilai $F$ tabel lebih tinggi dari $F$ hitung pada varian cutting speed dan nilai $F$ tabel kurang dari $F$ hitung pada varian feedrate dan depth of cut. Nilai ini 
menunjukkan bahwa tidak ada pengaruh dari cutting speed dan ada pengaruh dari feedrate dan depth of cut terhadap waktu proses permesinannya. Pengaruh dari masing - masing varian dijelaskan sebagai berikut:

(1). Hubungan cutting speed $\left(V_{c}\right)$ terhadap waktu proses pemesinan

Berdasarkan tabel Anova diketahui nilai F-hitung untuk varian cutting speed lebih kecil dari F-tabel (F-hitung $=1,00<\mathrm{F}$ tabel $=4,46$ ) dan nilai sig. $=0,505>0,05$. Hal ini menunjukan bahwa cutting speed tidak mempengaruhi secara signifikan terhadap waktu proses permesinan. Dari tabel pengukuran waktu proses permesinan dapat dibuat grafik hubungannya (Gambar 4), dapat dilihat bahwa dengan nilai pada faktor lain (feedrate dan depth of cut) yang sama atau konstan, cutting speed $=56520$ $\mathrm{mm} /$ menit memiliki mean waktu proses permesinan 122,75 menit, cutting speed = $75360 \mathrm{~mm} /$ menit memiliki mean waktu proses pemesinan 115,47 menit dan cutting speed $=94200 \mathrm{~mm} /$ menit memiliki mean waktu proses pemesinan 116,05 menit.

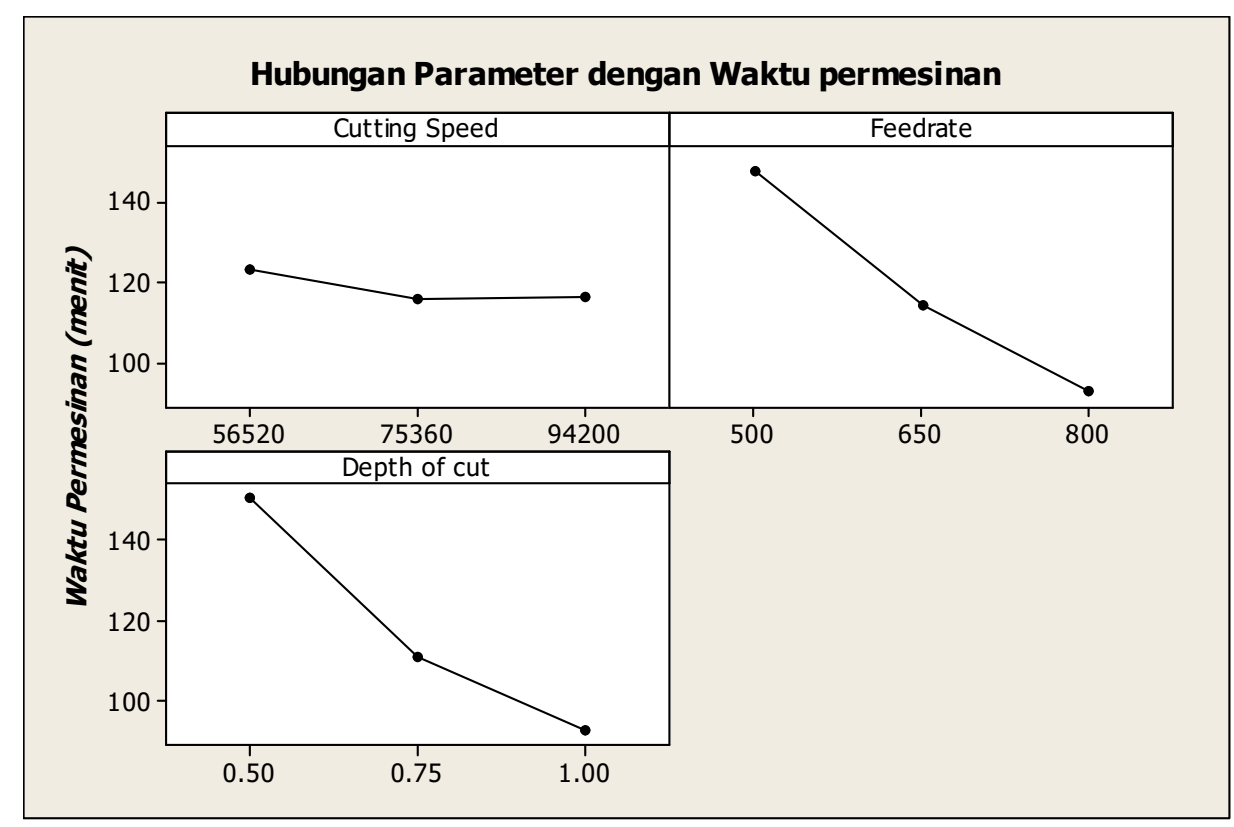

Gambar 4. Hubungan parameter permesinan terhadap waktu proses

(2). Hubungan feedrate (f) terhadap waktu proses pemesinan

Berdasarkan tabel Anova diketahui nilai F-hitung untuk varian feedrate lebih besar dari F-tabel (F-hitung $=46,53>\mathrm{F}$ tabel $=4,46)$ dan nilai sig. $=0,021<0,05$. Hal ini menunjukan bahwa feedrate mempengaruhi secara signifikan terhadap waktu proses permesinan. Dari tabel pengukuran waktu proses permesinan dapat dibuat grafik hubungannya (Gambar 4), dilihat bahwa dengan nilai pada faktor lain (cutting speed dan depth of cut) yang sama atau konstan, feedrate $=500 \mathrm{~mm} /$ menit memiliki mean waktu proses permesinan 147,56 menit, feedrate $=650 \mathrm{~mm} /$ menit memiliki mean waktu proses permesinan 113,88 menit dan feedrate $=800 \mathrm{~mm} /$ menit memiliki mean waktu proses permesinan 92,84 menit. Hal ini menunjukan bahwa adanya hubungan bahwa semakin besar feedrate, maka semakin singkat waktu proses permesinannya.

(3). Hubungan depth of cut terhadap waktu proses pemesinan

Berdasarkan tabel Anova diketahui nilai F-hitung untuk varian depth of cut lebih besar dari F-tabel (F-hitung $=53,63>\mathrm{F}$ tabel $=4,46)$ dan nilai sig. $=0,018<0,05$. Hal ini menunjukan bahwa depth of cut mempengaruhi secara signifikan terhadap waktu proses permesinan. Dari tabel pengukuran waktu proses permesinan dapat di buat grafik hubungannya (Gambar 4), dapat dilihat bahwa grafik cendrung menurun 
secara linier dengan kemiringan negatif. Dari grafik dapat diketahui bahwa waktu proses permesinan akan turun dengan bertambahnya nilai depth of cut pada setiap pemotongannya. Dengan nilai pada faktor lain (cutting speed dan feeding) yang sama Analisa Regresi

Dari hasil yang didapatkan diketahui bahwa hubungan cutting speed dengan waktu proses permesinan telah memenuhi asumsi distribusi secara normal seperti terlihat pada Gambar 5,6,7, bahwa tampak secara visual gambar pada grafik dimana titik-titik hasil data atau konstan, depth of cut $=0,5 \mathrm{~mm}$ memiliki mean waktu proses permesinan 150,59 menit, depth of cut $=0,75 \mathrm{~mm}$ memiliki mean waktu proses permesinan 111,14 menit dan depth of cut $=1 \mathrm{~mm}$ memiliki mean waktu proses permesinan 92,55 menit. percobaan masih berada dalam rentang nilai yang didefinisikan yang menunjukkan hubungan fungsional negatif dengan persamaan regresinya yaitu Waktu $=131.5$ 0.000178 Cutting Speed, begitu juga yang terjadi untuk feedrate dan depth of cut dengan persamaan regresinya yaitu $W a k t u=236.7$.

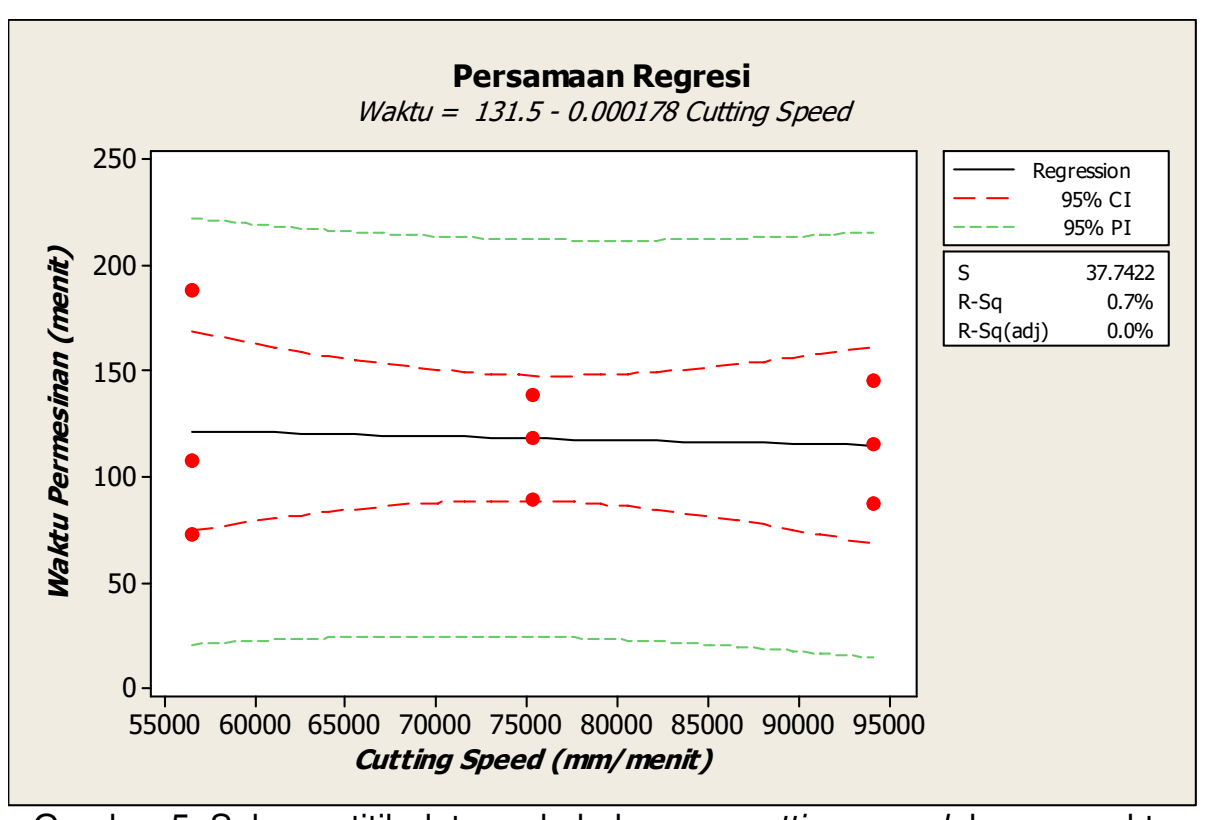

Gambar 5. Sebaran titik data pada hubungan cutting speed dengan waktu

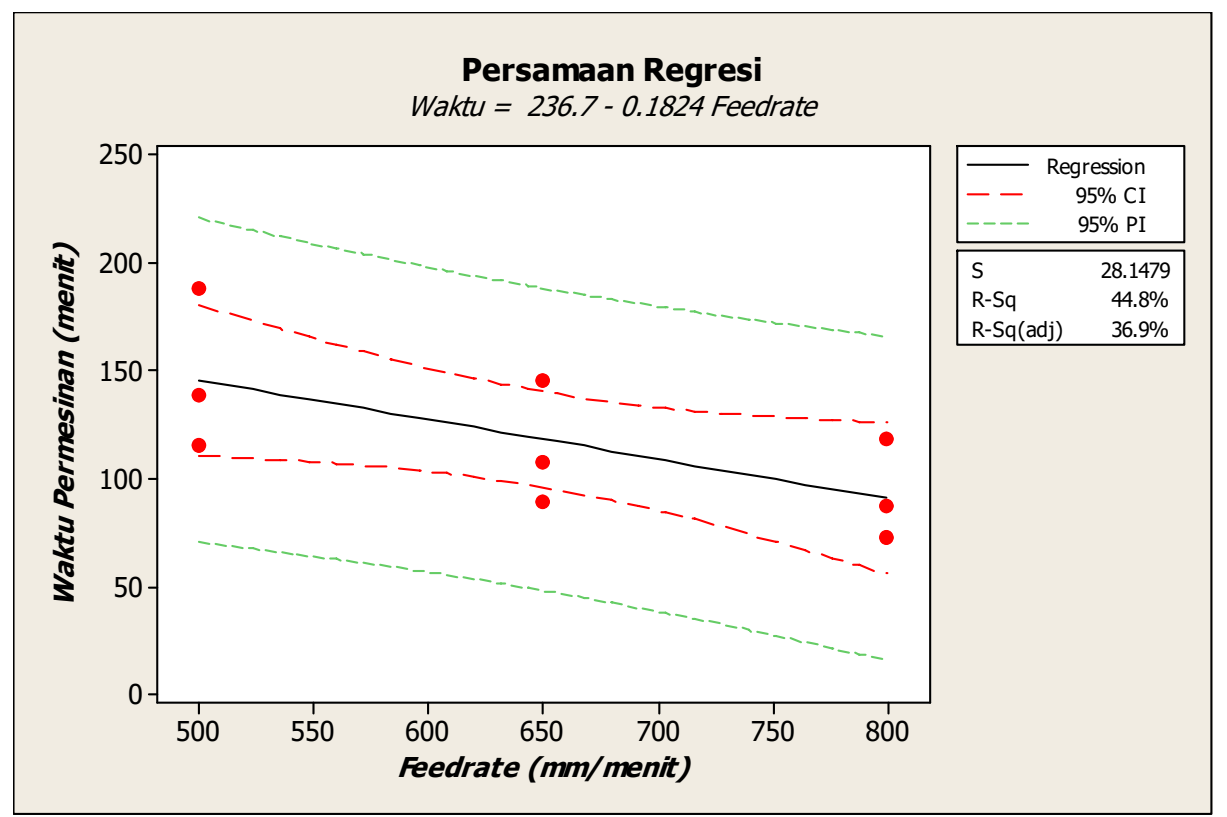

Gambar 6. Sebaran titik data pada hubungan feedrate dengan waktu 
0.1824 Feedrate, Waktu $=205.1-116.1$ Depth of cut. permesinan. Seperti yang telah ditunjukan dalam grafik (Gambar 4) bahwa semakin besar nilai cutting speed tidak akan mempengaruhi waktu proses permesinannya secara signifikan karena tidak tetapnya grafik secara linier antara level rendah ke tinggi yang cenderung naik turun pada tiap levelnya. Level low menghasilkan mean waktu proses

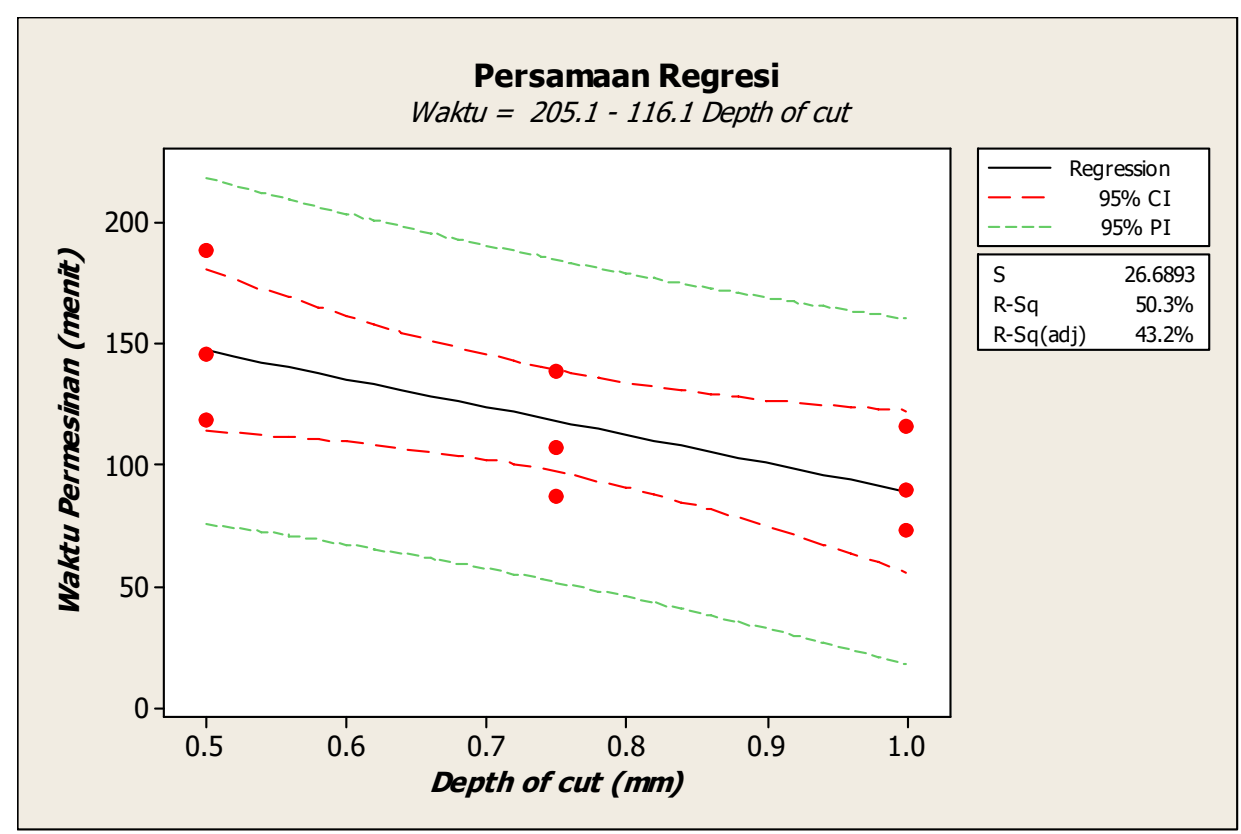

Gambar 7. Sebaran titik data pada hubungan depth of cut dengan waktu

Pembahasan hasil dengan software CAM Cutting speed berpengaruh secara tidak nyata terhadap waktu proses permesinan 122,75 menit, level medium 115,47 menit sedangkan pada level high 116,05 menit. Pemilihan nilai cutting speed

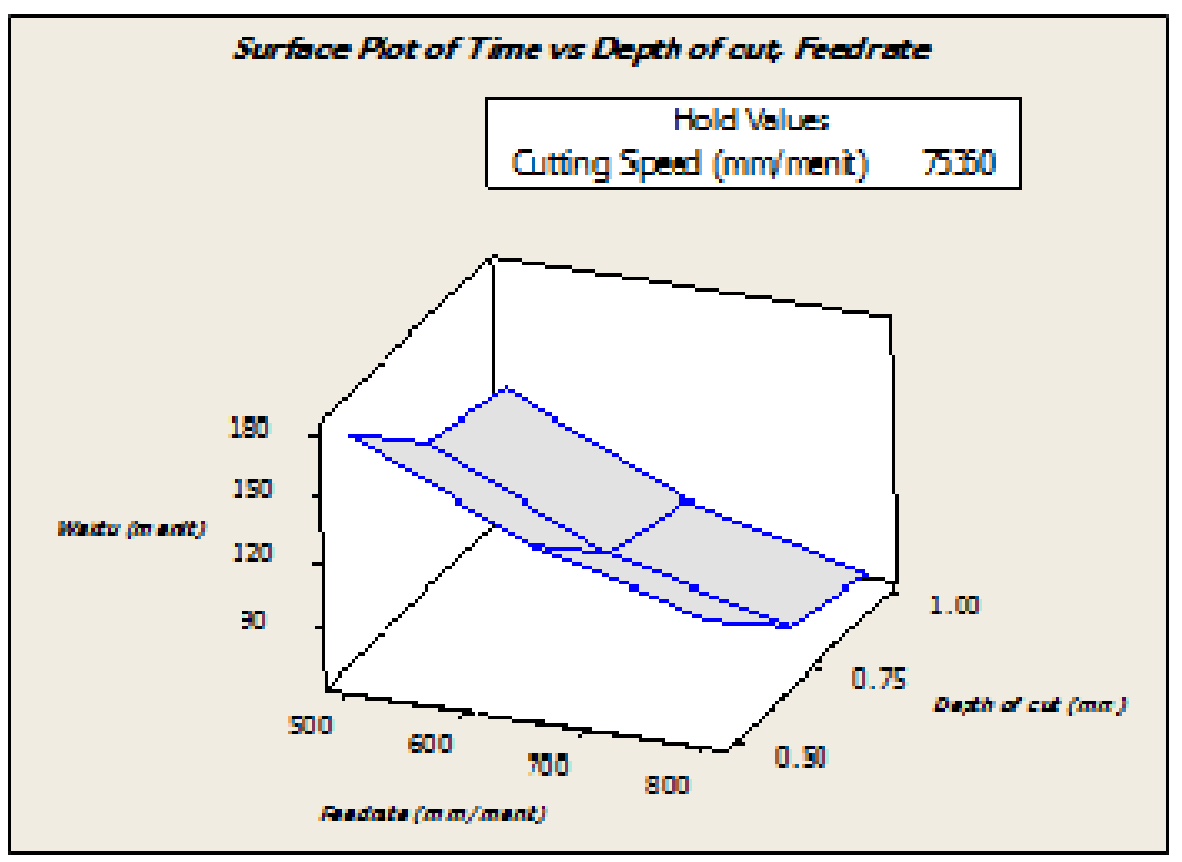

Gambar 8. Konfirmasi kondisi waktu optimal. 
akan menentukan nilai putaran spindel secara linier, dimana semakin besar nilai cutting speed dan memperbesar nilai putaran dalam rpm. Pada persamaan waktu proses permesinan, putaran spindel bersama dengan feedrate akan menentukan waktu proses permesian. Feedrate secara signifikan mempengaruhi waktu proses permesinan. Seperti yang telah ditunjukan dalam grafik (Gambar 4) bahwa semakin besar nilai feedrate semakin mempercepat waktu proses permesinan. Level low menghasilkan mean waktu proses permesinan 147,56 menit, level medium 113,88 menit selanjutnya pada level high 92,84 menit. Depth of cut secara signifikan mempengaruhi waktu proses permesinan. Seperti yang telah ditunjukan dalam grafik (Gambar 4) bahwa semakin besar nilai depth of cut akan semakin mempercepat waktu proses permesinan. Level low menghasilkan mean waktu proses permesinan 150,59 menit, level medium 111,14 menit sedangkan pada level high 92,55 menit. Pada permesian CNC milling secara sistematis depth of cut akan menentukan barapa kali suatu kontur akan diselesaikan.

Dalam penelitian ini penentuan kondisi optimal mengunakan bantuan program Minitab 16 yang berdasarkan hasil dari nilai mean level dari masing-masing varian (Tabel 9) sehingga diketahui pengaturan parameter permesinan yang optimal pada kondisi cutting speed level $2=75360 \mathrm{~mm} /$ menit, federate level $3=800 \mathrm{~mm} / \mathrm{menit}$, depth of cut level $3=$ $1 \mathrm{~mm}$, grafik pada kondisi tersebut terlihat pada Gambar 8. Kondisi optimal dalam penelitian ini dilihat berdasarkan dari lamanya waktu yang ditempuh dalam proses permesinannya. Hasil percobaan ini ditunjukkan pada Tabel 10.

Tabel 10. Hasil pengukuran dari waktu optimal.

\begin{tabular}{cccc}
\hline Toolpath & $\begin{array}{c}\text { Time } \\
\text { (menit) }\end{array}$ & $\begin{array}{c}\text { Feed cut } \\
\text { length } \\
\text { (mm) }\end{array}$ & $\begin{array}{c}\text { Rapid } \\
\text { length } \\
\text { (mm) }\end{array}$ \\
\hline Face & 6,73 & 5143,97 & 1239,59 \\
Rough & 47,67 & 37217,87 & 4368,32 \\
Finish & 17,52 & 13598,66 & 2640,24 \\
Total & 71,92 & 55960,5 & 8248,15 \\
\hline
\end{tabular}

\section{Hasil percobaan pada Mesin CNC (Sampling)}

Berdasarkan prosedur dalam pelaksanaan penelitian, proses percobaan pada Mesin CNC mengacu pada pemilihan parameter yang optimal yang didapatkan dari analisis data yaitu spindle speed $=2000 \mathrm{rpm}$; feedrate $=800 \mathrm{~mm} /$ menit; depth of cut $=1$ $\mathrm{mm}$. Adapun tahapan dalam percobaan pada mesin CNC berdasarkan proses pengerjaan masing-masing toolpath yakni face dengan facemill $40 \mathrm{~mm}$, rough dengan end mill 12 $\mathrm{mm}$, finish dengan end mill $6 \mathrm{~mm}$, hasil dari tiap-tiap proses pengerjaan yang terjadi terlihat pada Gambar 9.

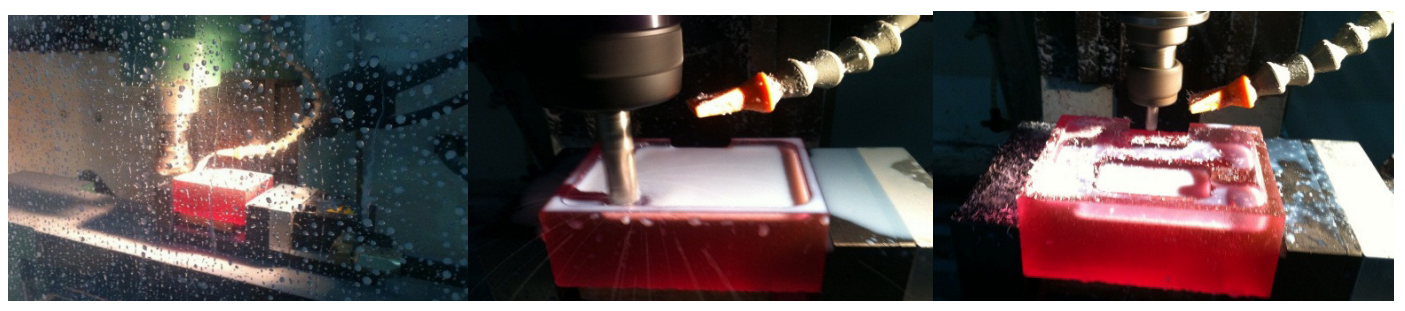

(a)

(c)

Gambar 9. Hasil tampilan percobaan pada Mesin CNC Milling (a).facing,(b).roughing, (c).finishing.

\section{Pembahasan percobaan pada mesin CNC} Percobaan pada Mesin CNC yang dilakukan pada penelitian ini dengan mengunakan Mesin CNC Milling Mitshubishi M70, yang berdasarkan dengan parameter hasil waktu optimum yang didapatkan pada analisa data yang telah dilakukan sebelumnya. Proses percobaan pada mesin CNC ini merupakan rangkaian dari tahapan proses pada penelitian ini yang sebelumnya proses pembuatan gambar benda kerja dengan mengunakan Software Solidworks yang kemudian ditransfer ke Software Mastercam $X$ sebagai perantara untuk proses perencanaan dan pembuatan lintasan pahat (Toolpath Geometry) dengan dilakukan simulasi terlebih dahulu sampai didapatkan $G$ Code, selanjutnya G Code tersebut ditransfer 
ke Mesin CNC Milling Mitshubishi M70 melalui USB Flash.

Pada tahapan percobaan yang dilakukan pada Mesin CNC, dibagi dalam tiga tahapan proses permesinan yaitu pengerjaan permukaan (Facing), pengerjaan kasar (Rough) dan pengerjaan halus (Finishing). Proses permesinan dengan pengerjaan kasar kemudian dilakukan dalam 5 bagian berdasarkan dengan toolpath masing masing yaitu; contour1, contour2, contour3, pocket1 dan pocket2, data pengukuran waktu proses pemrograman pada pengerjaan kasar terlihat pada tabel 11. Adapun pengunaan parameter permesinan dan toolpath yang digunakan mengacu pada yang telah ditetapkan pada metode penelitian dan hasil dari simulasi dengan software Mastercam $X$.

Tabel 11. Data hasil pengukuran waktu proses Rough.

\begin{tabular}{cc}
\hline Rough Toolpath & Time (menit) \\
\hline Contour 1 & 19,95 \\
Contour 2 & 5,21 \\
Contour 3 & 8,26 \\
Pocket 1 & 9,40 \\
Pocket 2 & 4,75 \\
Total & 47,57 \\
\hline
\end{tabular}

Proses permesinan dengan pengerjaan halus (Finishing) dilakukan dalam 4 bagian berdasarkan dengan toolpath masing masing yaitu; contour1, contour2, pocket 1 dan pocket2, data pengukuran waktu proses pemrograman pada pengerjaan halus terlihat pada tabel 12. Adapun pengunaan parameter permesinan dan toolpath yang digunakan mengacu pada yang telah ditetapkan pada metode penelitian dan hasil dari simulasi dengan software Mastercam $X$, selanjutnya pada tabel 16 menunjukkan total hasil pengukuran waktu proses permesinan yang dilakukan pada percobaan menggunakan mesin CNC milling Mitshubishi M70.

Tabel 12. Data hasil pengukuran waktu proses Finishing.

\begin{tabular}{cc}
\hline Finishing Toolpath & Time (menit) \\
\hline Contour 1 & 3,40 \\
Contour 2 & 5,82 \\
Pocket 1 & 6,26 \\
Pocket 2 & 2,40 \\
Total & 17,88 \\
\hline
\end{tabular}

Tabel 13. Data total hasil pengukuran waktu proses permesinan pada Mesin CNC.

\begin{tabular}{cc}
\hline Toolpath & Time $($ menit) \\
\hline Face & 6,72 \\
Rough & 47,57 \\
Finish & 17,88 \\
Total & 72,17 \\
\hline
\end{tabular}

\section{Perbandingan waktu hasil CAM dengan CNC Milling}

Hasil pengukuran waktu proses permesinan yang dilakukan pada mesin CNC Milling kemudian dilakukan perbandingan dengan waktu proses yang didapatkan pada proses CAM dengan software Mastercam X, adapun perbedaan hasilnya terlihat pada (Tabel 14) dimana waktu yang dihasilkan hampir persis sama, karena tidak adanya perbedaan waktu secara nyata antara proses pada CAM dengan proses pada mesin CNC diketahui pada proses CAM didapatkan waktu proses permesinannya yaitu 71,92 menit, sedangkan pada proses dengan mesin CNC didapatkan waktu proses permesinannya yaitu 72,17 menit. Sehingga diketahui selisih waktu yang terjadi yaitu 0,25 menit atau 15 detik dengan persentase $0,35 \%$. Hal ini menunjukkan bahwa adanya perbedaan waktu yang tidak signifikan antara proses pada CAM dengan proses pada mesin CNC. Hasil perbandingan tersebut memberikan arti bahwa tanpa dilakukanya percobaan lansung pada mesin CNC, waktu proses permesinannya sudah bisa disimpulkan dari hasil percobaan simulasi pada proses CAM dengan mengunakan software Mastercam $X$.

Tabel 14. Data perbandingan waktu proses permesinan pada CAM dan Mesin CNC.

\begin{tabular}{ccc}
\hline \multirow{2}{*}{ Toolpath } & \multicolumn{2}{c}{ Time (menit) } \\
& Proses CAM & Proses CNC \\
\hline Face & 6,73 & 6,72 \\
Rough & 47,67 & 47,57 \\
Finish & 17,52 & 17,88 \\
Total & 71,92 & 72,17 \\
\hline
\end{tabular}

\section{KESIMPIULAN DAN SARAN \\ Kesimpulan}

Dari hasil eksperimen dan Analisa Statistik dengan Anova pada taraf signifikansi $5 \%$ didapatkan hasil:

1. Bahwa cutting speed berpengaruh secara tidak nyata dengan kontribusi persentase $0.92 \%$, sementara feedrate dan depth of cut berpengaruh secara signifikan terhadap waktu proses 
permesinan dengan kontribusi persentase $43 \%$ dan $49.56 \%$.

2. Waktu proses permesinan optimal yang dihasilkan dari simulasi software CAM adalah 71,92 menit, pada kondisi cutting speed $=75360 \mathrm{~mm} / \mathrm{menit}$, kondisi federate $=800 \mathrm{~mm} / \mathrm{menit}$, kondisi depth of cut $=1$ $\mathrm{mm}$. Selanjutnya hasil percobaan lansung pada mesin CNC Milling menunjukkan adanya perbedaan yang tidak signifikan dengan persentase $0,35 \%$.

\section{Saran}

Adapun saran yang dapat diberikan setelah melakukan penelitian adalah sebagai berikut:

1. Pada penelitian selanjutnya, dapat dilakukan dengan optimasi menggunakan tambahan variabel respon seperti kualitas produk.

2. Penelitian ini dapat dilakukan pengembangan dengan melakukan perbandingan dengan mengunakan software CAD/CAM yang lain.

3. Penelitian ini masih bisa dikembangkan lagi dengan cara menambah parameter lain seperti jenis material benda kerja, sebagai perbandingan.
4. Untuk menghasilkan waktu proses permesinan optimal pada mesin CNC milling dapat dilakukan dengan cara mengoptimalkan nilai depth of cut dan feedrate.

\section{DAFTAR PUSTAKA}

Draganescu F., Gheorghe M., Doicin C.V., 2003, Models of machine tool efficiency and specific consumed energy, Journal of Materials Processing Technology, Vol.141, No.1, pp. 9 - 15.

Krar S., Gill A., 1999, Computer numerical control programming basics, Industrial Press Inc. New York.

Ricky, 2009, Computer aided manufacturing (CAM), tersedia di https:// r1ck.wordpress.com/2009/11/23/compu ter-aided-manufacturing-cam.

Rochim T., 1993, Teori \& teknologi proses permesinan, Higher Education Development Support Project, ITB, Jakarta.

Sukardi, 2004, Metodologi Penelitian, PT. Bumi Aksara, Jakarta.

Wijanarka B.S., 2011, Teknik permesinan frais CNC, Universitas Negeri Yogyakarta. 